\section{Entrevista a Hernán Larraín: la ratificación de la Corte Penal en Chile}

Este comentario, junto a los documentos que analiza, está disponible en www.anuariocdh.uchile.cl

\# ernán Larraín es chileno, abogado, licenciado en derecho por la Pontificia Universidad Católica de Chile. Master en Leyes (LL.M.) en la London School of Economics. Desde 1971 hasta la fecha desempeña labores docentes en la Facultad de Derecho de la Pontificia Universidad Católica, siendo nombrado Profesor Titular en 1984. Ha publicado artículos y ensayos en materias educacionales, culturales, jurídicas y políticas. En las elecciones de diciembre de 1993 fue elegido Senador y fue reelegido en diciembre de 2001 con la primera mayoría, para el período 2002-2010, y nuevamente reelecto con la primera mayoría nacional para el período 2010-2018. Fue Presidente del Senado marzo 2004-marzo 2005. Actualmente preside la Comisión de Relaciones Exteriores e integra la de Constitución, Legislación y Justicia del Senado. Ha sido redactor y columnista del diario "El Mercurio", de la "Revista Ercilla" y del "Diario Financiero", entre otros.

Diego Pardo: el Estatuto de Roma goza de una amplia aceptación internacional. Para entrar en vigencia se requería de la ratificación de 60 Estados, cifra alcanzada ya el año 2002. En el año 2009 se produce la ratificación de Chile, contando el estatuto a esa fecha con la ratificación de aproximadamente 120 Estados. A su juicio, ¿cuáles son las razones o beneficios que trae para Chile ratificar el Estatuto de Roma?

Hernán Larraín: La ratificación es muy importante para Chile y para la causa de los Derechos Humanos. Existen varias aproximaciones al tema. La primera, es que hay delitos de mucha gravedad que por distintas razones -ya sea de carácter político, conveniencia o simplemente por la manera de entender los límites fronterizos- sufren impedimentos para articular una cierta racionalidad en su juzgamiento, para que reciban su correspondiente sanción. Pensando que Chile tuvo una experiencia amarga en cuanto a Derechos Humanos, y siendo un país que siempre ha demostrado una tradición de respeto por los derechos y las libertades, ésta era una oportunidad para hacer las cosas bien y adherirse de una manera realmente auténtica a este tratado, para darle no solamente un respaldo más, sino que un respaldo muy significativo y comprometido.

Había que superar algunos puntos que no son menores. Estamos entrando aquí a un nivel de desarrollo del derecho público que trasciende las fronteras de los Estados y no descansa en ellas, sino en cuestiones más particulares y específicas. Por lo tanto, era conveniente articular un proceso de ratificación que fuese razonable. Y a nosotros nos parecía que si se lograban articular estas dos cosas -la superación de aquellos impedimentos, como de cuestiones específicas-, se podría avanzar con mucha fuerza en aprobar este proceso. Y, creo yo, que mediante esta superación se le da una cierta validez a la justicia internacional, si acaso pudiéramos señalar que existe, para un

\footnotetext{
* Egresado de la Facultad de Derecho de la Universidad de Chile. Asistente de Dirección del Centro de Derechos Humanos y ayudante de los departamentos de Ciencias del Derecho, Derecho Penal y Derecho Procesal de la misma casa de estudios.
} 
cierto atisbo de justicia, para que ciertos hechos que son a todas luces intolerables e inaceptables no quedaran en la impunidad.

Así que me parece que ahí había un hecho de mucha trascendencia, por la causa misma y además por las circunstancias nacionales que le daban a nuestra aprobación un especial significado.

DP: Al fin y al cabo, esas circunstancias internacionales y la articulación de la que usted habla, se produjo el año 2009 con la aprobación casi unánime de una Reforma Constitucional y con la ratificación también casi unánime del Estatuto de Roma. ¿Qué condiciones políticas generaron ese amplio consenso político que tanto tardó?

HL: Tardó por distintas razones. Algunas nuestras y otras externas. La primera razón que bloqueó el avance de este proyecto fue la situación de Estados Unidos, que, a través de su legislación estableció una especie de sanción a los países que firmaban este acuerdo. Teniendo Chile compromisos que pudiesen afectar su desarrollo en el ámbito de las Fuerzas Armadas, el Gobierno postergó esta decisión y dejó un espacio para comprender a cabalidad qué consecuencias traería la ratificación, y para asegurarse además que, si al final se tomaban las decisiones a pesar de esas eventuales consecuencias, ellas no pudiesen generar un conflicto realmente grave que pudiera, por ejemplo, impedir el funcionamiento de una rama de las Fuerzas Armadas.

Despejado ese episodio, surgió la necesidad de despejar otro, que fue levantado por nosotros. En nuestro ámbito político, con distintos matices, existía la voluntad de dar el paso, pero no de entregar la jurisdicción sobre esos delitos en primera instancia, por decirlo con simpleza, a la Corte Penal Internacional. Por eso, el planteamiento que nosotros hicimos fue que, previo a la entrada en vigencia de este Estatuto, debiéramos tener tipificados los mismos delitos del estatuto en nuestra Legislación interna, de manera que se Ilenara aquel vacío. Era bastante insólito que nosotros no tuviéramos legislados los delitos de genocidio, lesa humanidad o crímenes de guerra. Con su incorporación en la legislación interna, nos parecía que se cumplía una condición para que nosotros adhiriéramos en plenitud al Estatuto de Roma, porque se cumplía, además y de esa manera, el sentido de dicha jurisdicción internacional, que no pretende ser directamente de primera instancia, sino que complementaria, es decir, que actúa cuando la jurisdicción nacional falla. Y, al menos desde mi punto de vista, si la jurisdicción nacional no pretende o es incapaz de conocer o juzgar delitos de esta naturaleza, es conveniente que actúe un tercero a que dichos crímenes gocen de impunidad. Resuelto el tema de nuestra legislación interna, pudimos dar el cauce al proyecto para que se hiciera realidad.

Esto requirió un acuerdo, pues estas materias son delicadas. Tocan, por diferentes lados, áreas de mucha sensibilidad. A algunos les preocupaba qué efectos iba a traer esta ratificación de cara a hechos del pasado, temiendo la posibilidad de agravarse la situación de los implicados; otros temían lo contrario, que esto podría de alguna manera exculpar a los implicados en dichos hechos. Ese fue un problema concreto por las sensibilidades que persisten en Chile en torno a los Derechos Humanos. Se resolvió, sabiamente a mi juicio, por medio de estos acuerdos y de esta tratativa, que los hechos que estaban actualmente en conocimiento de los Tribunales nacionales seguirían en manos de ellos, rigiéndose por las mismas leyes por las que habían comenzado ya a ser juzgados, con lo que el cuadro no cambió ni hacia uno ni otro sentido.

Así quedó zanjado el problema de fondo que, según mi visión, era avanzar asegurando la soberanía de Chile. Entendiendo que Chile es un país responsable, que posee una judicatura con tradición e instituciones que funcionan, no se debiera dejar las puertas abiertas, habiendo ratificado el Estatuto, para que cualquier hecho pudiera ser conocido por la Corte Penal Internacional, sino que, de darse estos hechos delictivos, ellos se regulen y juzguen por nuestra legislación y sean 
conocidos por nuestros Tribunales. La ratificación de la Corte Penal no es solamente conveniente, sino también una oportunidad para que Chile dé un testimonio sobre su soberanía.

DP: Chile fue uno de los primeros países latinoamericanos en firmar el Estatuto y, curiosamente, uno de los últimos en ratificarlo. ¿Qué costos cree tuvo que asumir Chile ante la comunidad internacional por este retraso, considerando que ella mira con atención nuestro accionar en materia de Derechos Humanos, por nuestra responsabilidad sobre el pasado reciente?

HL: No creo que tenga consecuencias mayores, pues si bien hay muchos países que han ratificado el Estatuto, otros muy importantes no lo han hecho. Se produjo aquí una discusión a nivel internacional sobre la conveniencia o no de ratificar el Estatuto; sobre su relación costo/beneficio; sobre si estábamos estableciendo tribunales sólo para juzgar países africanos o países subdesarrollados, etc. En fin, había un debate que ha puesto en entredicho el tema, de manera que no es que se haya aprobado a nivel mundial de manera espectacular y nosotros fuéramos el "patito feo". No fue así, sino que hubo -y subsiste- una importante discusión.

Como parlamentario he aprendido que muchas veces, cuando los proyectos se demoran, es porque los asuntos no están suficientemente maduros. Tenemos que ocupar el tiempo que necesitamos en estas materias, los tiempos internacionales (en este caso), son distintos a los nuestros, y las discusiones internacionales existentes eran diferentes a las nuestras. Hubiera sido deseable que no se demorara tanto. Podríamos haberlos hecho cinco años antes probablemente, pero al final no creo que haya tenido consecuencias negativas haberlo hecho después, porque lo hicimos, y lo hicimos bien y, además, demostrando que no estábamos simplemente haciendo un saludo a la galería, ni haciendo un acto populista o demagogia internacional, sino que hicimos un proceso maduro, con un consenso en lo profundo, resolviendo el tema bien. Lo mejor es enemigo de lo bueno. Repito, fue un proceso que para nosotros, internamente, fue muy positivo. Es cierto que hubo dos o tres parlamentarios que no le dieron su apoyo, lo cual es una pena, pero valoro yo mucho más que prácticamente la unanimidad haya dicho Sí, lo queremos en Chile. Fue un proceso de crecimiento para el país, y eso es algo muy valioso.

DP: Si lo interpreto bien, a su juicio, el amplio consenso que se logró en la ratificación del Estatuto supera cualquier tipo de costos que hubiera tenido su retraso.

HL: Exacto, en el entendido de que fue un proceso que sirvió para lograr un compromiso de todos los actores políticos, y eso me parece que tiene un valor mayor. No fue una imposición, ni fue aceptado con un bueno, ya, qué van a decir si no firmamos. No. Fue más bien como quiero hacerlo pues estoy convencido de que es bueno para Chile y para el mundo. Eso tiene un valor mayor a los costos que hubiesen podido existir.

DP: El proceso de ratificación y reconocimiento vivido para la Corte Penal Internacional fue anómalo o peculiar en un doble sentido: en primer lugar, se pidió tanto opinión al Tribunal Constitucional como a la Corte Suprema (esta última sin carácter autoritativo); y en segundo lugar, se decidió modificar la legislación interna con anterioridad a la entrada en vigencia del Estatuto, lo que es anómalo respecto de muchos otros tribunales o de muchas otras jurisdicciones internacionales que han sido reconocidas sin necesidad de modificar la Constitución. ¿Qué condiciones generan que la Corte Penal Internacional se haya tratado con esta anomalía o con esta diferencia frente al reconocimiento que se ha hecho de, por ejemplo, la Corte Interamericana?

HL: Yo no lo consideraría una anomalía, pues distintos países siguieron diferentes caminos para aprobar el Estatuto. Algunos lo aprobaron sin modificar la Constitución, pero otros sí la modificaron. 
En Chile, el Ejecutivo intentó aprobar el Estatuto sin modificar la Constitución, pero los diputados estimaron que esa forma no era la correcta y que se debía modificar la Constitución, porque implicaba una cesión de soberanía radicada exclusivamente en nuestros tribunales. Por lo tanto, estos diputados recurrieron al Tribunal Constitucional mediante un Recurso de Inconstitucionalidad. El recurso también fue un hecho que demoró, como un tercer elemento, la aprobación del Estatuto. Pero es justo admitir que tenían razón los diputados que estimaban como necesaria una reforma constitucional. Uno no puede dar por supuesto que la cesión de soberanía jurisdiccional, en el ámbito o instancia que sea, pueda ser simplemente materia de un acuerdo. Aquellos casos en que hemos cedido soberanía, por ejemplo, a la Corte Interamericana de Derechos Humanos, y también a instancias económicas entre otros varios casos, todos han sido dentro de nuestro ordenamiento constitucional, no simplemente a través de tratados. Me parece que en este caso era razonable hacerlo, y se hizo bien, y eso permitió evitar un problema que el día de mañana, cuando alguien pudiera aplicar esto, dijera pero cómo vamos a aplicar esto si no está dentro de nuestro ordenamiento constitucional. Eso hubiera sido un punto vulnerable. En segundo lugar, si bien es cierto se prefirió por el gobierno no realizar en forma previa cambios constitucionales ni legales, me parece que era perfectamente válido opinar lo contrario. Lo primero era imposible de sostener y así lo estimó nuestro Tribunal Constitucional; en cambio, lo segundo podría haberse hecho, pero sería en mi opinión contradictorio: no es correcto que una jurisdicción complementaria, al no haber ley, pueda intervenir directamente sin mediar la actuación de nuestros tribunales en el juzgamiento de hechos constitutivos de delito. Ello implica que esos delitos existen por el hecho de estar contenidos en el Estatuto, y eso también es muy discutible, pues si se analiza solamente desde el punto de vista de teoría penal, dicha tipificación es por mucho insuficiente, pues no tiene la precisión ni el rigor que tiene nuestra legislación penal interna. Por lo tanto, el esfuerzo que nosotros hicimos, y que hizo la Comisión que coordinaba Enrique Cury, fue el dar no solamente con los mismos delitos, sino que ellos se tipificaran en el mismo espíritu del Estatuto, pero con la precisión y rigor de nuestro derecho positivo. Creo que eso se logró. Así, no creo que el procedimiento haya sido anómalo, sino solamente distinto al de otros casos.

Recuerdo que cuando fui a La Haya estuve con el embajador mexicano, quien nos comentaba que en México, por ejemplo, se aprobó el tratado con una condición: que la entrega de una persona al tribunal para ser juzgada debía ser aprobada por el Senado. Australia, a su vez, lo hizo con una declaración complementaria. Cada uno siguió sus respectivos caminos. Uno podría preguntarse cuál es el camino obvio, pero no existen en esta materia caminos obvios. Porque cada uno tiene sus lógicas, justificaciones y miradas propias. Yo creo que nosotros tuvimos efectivamente estos tres puntos -la compra de los F-16, la sentencia del Tribunal Constitucional y la necesidad de modificar la legislación penal. El único externo de esos tres, fue el relacionado con Estados Unidos, y que el Gobierno estimó como prudencial, porque recién se habían adquirido los aviones F-16 y, por lo tanto, se sentía que podía debilitarse esa inversión si no se tenía seguridad de los abastecimientos y provisión de repuestos necesarios para que los aviones operaran. Lo determinó así el Gobierno y nos pareció prudente dejar pasar el tiempo hasta resolver ese tema. Los otros dos factores de retraso, en cambio, me parece que fueron necesarios para hacer bien las cosas bajo nuestro orden constitucional. Por otro lado, el tiempo tomado en ratificar el Estatuto nos permitió madurar el tema central de él. Cuando yo conversaba con alguna persona, me decía pero para qué queremos esto: vamos a tener un Tribunal metido en nuestra casa, vigilándonos. No era éste un tema menor ya que existe cierta desconfianza en los tribunales internacionales en cuanto se estima por algunos que sus nombramientos tienen una cierta influencia política, dada la forma cómo se designan a los jueces, hablando en términos generales. El vencer estos temores fue un proceso de madurez, como decía antes, un proceso de reflexión, de discusión, que nos sirvió para que la gente se sumara a esto de forma positiva y no obligada. 


\section{DP: ¿A usted le parecería que la forma en que se llegó al acuerdo político debería usarse gene- ralizadamente en los próximos tratados a los que Chile tenga que adherir?}

HL: Por supuesto que no. Yo creo que son procesos distintos. Por ejemplo, complementariamente al Estatuto, discutimos el Tratado sobre la Desaparición Forzosa de Personas, que había tenido idas y venidas por distintas razones. Sin embargo, en el Senado su ratificación fue un trámite. Cuando tú haces grandes modificaciones, como ocurrió en nuestro país en el caso de la Ley de Divorcio, ellas demoran mucho en salir. Se podría pensar que los parlamentarios son lentos o flojos, pero no es un problema de lentitud ni de flojera, sino que cuando las cosas no han madurado no avanzan. Hay ciertas leyes que demoran, como la Ley sobre el Bosque Nativo que demoró mucho e incluso se dictó con errores, pero aún así dimos un paso. ¿Por qué? Porque a veces no es siquiera un problema de mayorías, pues a veces están. Lo que falta es convicción sobre qué hay que hacer. Yo recuerdo haber estado trabajando en un proyecto de ley sobre fertilización in vitro para el que discutimos muchísimo. Pasaba el tiempo, mucho tiempo, un año, dos años, y no avanzábamos. Yo hablaba con los médicos, me movilizaba, hablaba con las clínicas y hospitales. ¿Y cuál fue la resolución? Es mejor no legislar; es mejor que esto quede entregado a los comités de ética de las clínicas, pues no tenemos cómo legislarlo. Entonces se puede apreciar que a veces los procesos legislativos no tienen que seguir un trámite estándar, donde se entra, se discute, se aprueba, etc. No, yo creo que las realidades hay que mirarlas en cada caso, sobre todo cuando son temas muy significativos. Para la Ley de Divorcio repentinamente hubo acuerdo, y se aprobó. Se trabajó en forma razonable. En el caso del estatuto ocurrió por razones distintas: la primera de orden constitucional; la segunda de política internacional (a propósito de lo de los Estados Unidos); pero, finalmente, cuando ya entramos en materia, ya no había explicaciones ni razones para demorar. Entonces se dio un proceso de maduración, un proceso de conversación, de disipación de temores (muchas veces heredados de fenómenos recientes), de problemas culturales, como el secretismo (que es una tradición en Chile), o el nacionalismo, por llamarlo de alguna manera: el pensar que detrás o sobre el Estado de Chile no hay nada. Ello también forma parte de una tradición jurídica. Entregar jurisdicción a la Corte Penal Internacional es un paso más allá de aquellos temas políticos derivados de períodos históricos recientes. Tiene que ver con una tradición jurídica que no quiere, que no cree o que desconfía de la internacionalización del Derecho.

DP: Finalmente, se logró con casi la unanimidad la ratificación del Estatuto a través de una reforma constitucional que reconoce la jurisdicción subsidiaria de la Corte Penal Internacional. A su juicio, ¿ese reconocimiento está hecho en términos satisfactorios o el acuerdo político al que se llegó no es enteramente satisfactorio desde la perspectiva que usted encarna?

HL: Desde mi perspectiva, fue completamente satisfactorio. Todo quedó muy entroncado con el Estatuto y eso me hace pensar que estamos ante una situación bien resuelta. Alguien podría decir que se podría haber resuelto de muchas maneras, pero las leyes y las decisiones que se toman son hechas por personas que no son perfectas, así que sus labores nunca van a ser perfectas, pero a mí me parece que el tema quedó bien zanjado.

\section{DP: Volviendo al Tribunal Constitucional. A su juicio, ¿cuál cree fue su rol y e importancia?}

HL: El validar que la delegación de jurisdicción es materia de Reforma Constitucional y, por lo tanto, que todo tratado que ceda jurisdicción a un tribunal internacional o extranjero en general, requiere de una reforma constitucional. Con ello estableció un principio que me parece importante actualmente: ante la universalización de los derechos y la proliferación de acuerdos de comercio, cuando se avanza en esa línea, cada paso, en especial los primeros, deben ser dados muy conscientemente. Lo resuelto por el Tribunal Constitucional establece un precedente para considerar prudente y razonable seguir ese camino de esta forma. 
DP: ¿Estima que el Tribunal Constitucional destrabó el debate? ¿Se hubiera logrado la ratificación en el plazo en que se logró sin su intervención? ¿De qué manera propició un logro en términos satisfactorios?

HL: Yo creo que el Tribunal Constitucional obligó a enfrentar el tema derechamente. Porque muchas veces hay quienes plantean este tipo de objeciones para evitar pronunciarse sobre el fondo, para dilatarlo. Quien lo haya hecho con esa intención se equivocó, pues esta cuestión de todas maneras había que abordarla y había que asumirla en un minuto. Zanjado el tema por el Tribunal, no quedaba más que asumirlo o derechamente rechazarlo, si acaso esa era la voluntad de alguien. Por eso insisto: el episodio con Estados Unidos, que demoró la ratificación, permitió tener más tiempo para adquirir convicción, pero sobre todo, para definir que en un minuto dado, eso era lo que había que hacer.

DP: Esa definición de la que usted habla es un punto muy interesante, pues dentro de la tramitación ciertos sectores plantearon críticas al rol que había jugado el Tribunal Constitucional, en el sentido de que al opinar o resolver este tipo de materias se superpone al Poder Legislativo, a su capacidad política y de representación y, por lo tanto, se constituye como un poder que puede estar por sobre la decisión política que se tome.

HL: Esa es una discusión más vieja que el hilo negro, porque el problema de la interpretación de la ley o de la Constitución siempre puede dar espacio para que el juez vaya más allá de la norma y que cree su propia norma. Ese riesgo es inevitable: no podemos evitar que los tribunales interpreten la Ley. Al contrario, la interpretación es un proceso que da sentido creativo a la labor judicial. En la medida en que la ley esté bien hecha, en la medida en que las reglas de interpretación sean claras, siempre habrá ese espacio para la interpretación. Éste puede ser el lugar para que alguien la cuestione o critique, pero, hablando en castellano, eso no significa que el Tribunal Constitucional, o que los tribunales de justicia sean órganos constituyentes o legisladores. ¿Puede ocurrir que los tribunales de justicia vayan más allá de su ámbito, o del ámbito específico otorgado por la ley? Sí, es posible, mas no creo que éste sea el caso.

DP: La crítica a veces se plantea desde otro punto de vista, no desde la preocupación que existe sobre el poder que puede tener en ciertos casos el Tribunal Constitucional, sino desde la falta de poder, de capacidad o madurez que puede tener el Poder Legislativo en la definición de ciertas cuestiones de material constitucional. ¿A usted le parece que esa opinión también es desacertada?

HL: No creo que esa crítica tenga sentido, pues supone o presume la incapacidad del Congreso para resolver o hacer las cosas bien. Siempre hay rendijas por donde uno puede tener una mirada nueva o distinta, pero yo creo que las cosas, en la línea gruesa, son más sencillas. Aquí hubo un proceso que se objetó por un motivo que el Tribunal consideró razonable. Siempre habrá quienes quieran usar al Tribunal Constitucional para doblar la mano al Legislador, o al revés, recurrirán a él para defenderse de presuntas actuaciones indebidas o para dilatar las acciones del Ejecutivo. Pero al final, con todos los errores, las cosas van teniendo la aplicación del sentido común y ciertas cosas se hacen con un mínimo de buena fe, de decencia, de mirada de país. Hay que tener un poco más de confianza en el ser humano. Es cierto que debemos estar llenos de controles, para evitar que este débil sujeto tenga una caída y cometa errores. Es así, es como somos. No pretendamos ser súper hombres, si sólo somos hombres. 
DP: Quiero terminar retomando un punto que habíamos tocado al inicio. Las celebraciones de estos tratados de Derechos Humanos siempre son polémicas desde el punto de vista de la política internacional. En el proceso de ratificación que se vivió en Chile, se han dado dos niveles de polémica. El primero, que usted ya mencionó, es el episodio de los F-16 con Estados Unidos. El segundo, es la desigualdad existente entre algunos Estados muy fuertes, por ejemplo, los miembros del Consejo de Seguridad de Naciones Unidas, que no han ratificado el Estatuto y aquellos países pequeños que sí lo han hecho. Esta desigualdad, se critica, alimenta la sensación de que estamos ratificando un tratado que simplemente sirve para preocuparnos y juzgar países subdesarrollados. Y esas son críticas que se plantearon dentro de la discusión del Estatuto. ¿Qué opinión le merecen esas críticas? Y me interesa saber en particular si la forma en que actuó Chile en este punto lo ubica en una posición para seguir acciones concretas de rechazo frente a otros países que tratan este tema con desigualdad.

HL: Obviamente hay ahí una situación de desigualdad. Eso fue analizado, porque es muy realista asumirlo. La última intervención del Tribunal fue hecha respecto de un país, Darfur, que no ha aprobado su integración a esta Corte, ni su jurisdicción. Sin embargo, el Consejo de Seguridad puede pedir a la Corte Penal Internacional, respecto de un lugar donde estima existen violaciones tipificadas en el Estatuto, que actúe. Y la paradoja es que lo pidieron países que no han firmado respecto de otro país que tampoco ha firmado y, sin embargo, le dan la jurisdicción a la Corte. Es absurdo. Es, obviamente, una debilidad del sistema. Pero me parece que, como en todas las cosas, hay países como Estados Unidos a los que les costará asumir por muchos años situaciones de esta naturaleza, porque todavía está la sensación, inconsciente a lo mejor, o consciente para algunos, de que son los guardianes del mundo, y como guardianes no tienen quien los pueda limitar ni sancionar. En esto, Estados Unidos ha sido muy frío. Sobre la base de defender los intereses de los ciudadanos norteamericanos, en cualquier lugar del mundo, han buscado evitar todo compromiso de esta naturaleza.

¿Qué podemos hacer nosotros? No mucho como país, porque no tenemos una gran influencia a nivel mundial. Pero obviamente en la medida en que se van sumando voces la situación empieza a cambiar. Y yo creo que incluso Estados Unidos, bajo la presidencia de Obama, permite pensar que asumirá una actitud distinta respecto del mundo, no restringida a hablar del multilateralismo, sino practicándolo. Veremos si por esa senda, con el tiempo, se llega a cierta racionalidad. Pues desde el momento en que estos países que no han firmado, piden a la Corte Penal que actúe en otro país, podemos asumir que creen que hay allí una cierta legitimidad en lo que se hace, y, por lo tanto, validan su actuar.

Sería muy doloroso que el actuar de la Corte se circunscribiera nada más que a los países africanos o a ciertas realidades muy subdesarrolladas. Aunque el hecho que se dé una situación de esta naturaleza en un país desarrollado, como el mismo Estados Unidos, sería algo muy excepcional (porque los americanos son muy respetuosos de sus instituciones, de su democracia y de su derecho); si se llega a dar, y Estados Unidos mirara el techo en ese escenario, espero que la comunidad internacional haga fuerza moral, corrigiendo estas desigualdades. 